\title{
THE CONCEPT OF CLOUd OF THINGS FOR OVERCOMING THE SHORTCOMINGS OF EXISTING TECHNOLOGIES
}

\author{
Kresimir Rakic \& Zeljko Seremet
}
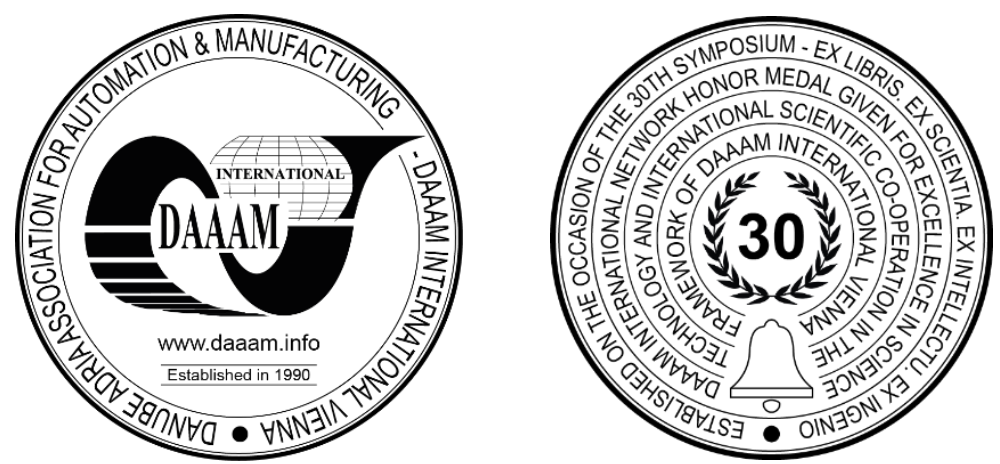

This Publication has to be referred as: Rakic, K[resimir] \& Seremet, Z[eljko] (2021). The Concept of Cloud of Things for Overcoming the Shortcomings of Existing Technologies, Proceedings of the 32nd DAAAM International Symposium, pp.0048-0051, B. Katalinic (Ed.), Published by DAAAM International, ISBN 978-3-902734-33-4, ISSN 1726-9679, Vienna, Austria

DOI: $10.2507 / 32$ nd.daaam.proceedings.007

\begin{abstract}
This paper describes and explains the need to integrate state-of-the-art computing technologies, the Internet of Things and cloud computing. The synergy of these technologies, the Cloud of Things, represents a new aspect of the use of everyday objects connected to the Internet and with each other and gives a new dimension to the possibilities of building smart resources.
\end{abstract}

Keywords: Information Society; Internet of Things; Cloud Computing; Cloud of Things.

\section{Introduction}

The birth of the personal computer in the 1970s, the graphical user interface in the 1980s, the World Wide Web in the 1990s and today the Internet of Things have launched our global society into the so-called information age. For the vast majority of people, digital change happens outside of their conscious perception. They are faced with the ever-changing requirements and needs posed to them. They need digital identification cards to communicate with government institutions; they feel the need to own a smartphone or maintain a page on a social network to stay in touch with their family and friends. At the same time, the technologies and processes behind these changes have become smaller, more complex, and more hidden in our everyday physical environment [1].

The amount of information today, practically every day, exceeds the situation from previous days. This fact is reflected in the explosion of media channels and products, the accelerated informatization of society, the development of education and the growing interest in information-related occupations. Living in the information age, we have become an information society.

The information society is a term for a society in which the creation, distribution, use, dissemination, integration and management of information have become the most important cultural, economic and political activity. The goal of the information society is to achieve a global competitive advantage, using information technology in a creative and useful way [2]. What is implicit in this term, in the way it is more widely used, is the pervasive nature of some digital information technologies, as well as our personal and professional dependence on computers and the Internet. When talking about the information society, people are likely talk of the incredibly fast ways in which digital communication has developed in the recent decades, and on the impact it has had on their lives and habits [3]. 
In 2020, the amount of data on the Internet hit 40 zettabytes. A zettabyte is about a trillion gigabytes [4]. Most of this data is first captured and created by humans - by typing, pressing a capture key, taking a digital picture, or scanning a barcode. However, people have limited time, attention and accuracy - all of which means that they are not very good at collecting data about things in the real world. People, like their environment, are physical. Our society is based on physical things, not on ideas or information. Ideas and information are important, but things are more important.

Yet today's information technology depends so much on data coming from humans that our computers know more about ideas than things. If we could train computers to know about things, based on data they collected independently, directly from those things, without our help, we could track and count everything, greatly reducing waste, losses and costs. We would know when to replace, repair, or recall things and, in general, manage them better and more efficiently [5]. But, in fact, we can. The solution to this problem is the Internet of Things.

\section{Concept of Internet of Things}

The basic concept of the Internet of Things (IoT) is the ability to upgrade everyday objects with identification, sensory, network and process capabilities that will enable them to communicate with each other, as well as communicate with other devices and services over the Internet, to achieve its purpose [6]. These objects are usually called "smart objects" because they require minimal human intervention to generate and exchange data, and they have capabilities for data collection, analysis and management [7].

The IoT represents the evolution of the use of existing technologies: Radio Frequency Identification (RFID) technologies, sensor networks, device communication, etc., in terms of the number and type of devices, as well as connecting the network of these devices via the Internet [8]. Over the past decade, the IoT has garnered significant attention from both academia and industry. The main reasons behind this interest are the opportunities that the IoT will offer. The IoT describes a world in which all objects, i.e., smart objects, are connected to the Internet and communicate with each other with minimal human intervention. The ultimate goal is to create a "better world for all people", in which the objects around us will know what we love, what we want, and what we need, and will act accordingly without explicit instructions. In its periodic report, Cisco predicts that in the next 10 years, the IoT will generate up to 500 billion devices connected to the Internet and to each other. This development will contribute to higher productivity, create new business models and generate new revenue streams [9]. Areas of application of IoT technologies are numerous and diverse, and IoT solutions are expanding every day and today find their place in almost all areas of human activity [10][11].

The most prominent areas of application include, for example, the smart industry, in which the IoT is a communication channel for the collaboration of smart manufacturing systems, with each other and with people. This application is referred to as Industry 4.0 [12]. In the field of smart homes and buildings, security systems, intelligent thermostats and other IoT technology solutions are receiving a lot of attention. Research in the field of smart energy consumption focuses on smart electricity, gas and water meters. Smart transportation solutions include, among other things, fleet tracking and mobile ticket sales [13]. In the field of smart health, applications on patient surveillance and chronic disease management stand out [14]. In the context of smart city projects, solutions such as monitoring the availability of parking spaces in real-time, intelligent street lighting, etc. are being explored [15].

The number of devices connected to the IoT is rapidly increasing, and with this increase grows the amount of data that needs to be collected, processed and stored. The need for storage space will soon not be able to be met locally because the devices at the IoT end are, as a rule, of the low vein and modest capabilities. The importance of the collected data and their efficient use goes beyond simple processing intending to form information and knowledge but should make them a means of wisdom for the user. Nor can this be accomplished by the limited capabilities of devices on the IoT side. A possible solution is the lease of storage space and processing power that can be achieved with the technologies of cloud computing [16].

\section{Cloud Computing}

Cloud computing represents the delivery of various services, i.e., tools and applications, via the Internet, including data storage, servers, databases, networking and the necessary software. As an alternative to storing and processing data on a proprietary hard drive or local storage device, cloud storage allows you to save it in a remote database, access that data, and software applications to work with it [17].

Cloud computing is called such because the information it accesses is located remotely, in virtual space, or the cloud. The user does not have to be in a specific place to access and be able to work with the data, which allows him to work remotely. This approach to storing and processing data takes away the demanding work from the device you are carrying or sitting at it and work. All business moves into computer clusters far away in cyberspace. The Internet is becoming a cloud, our data, business and applications are available from any device you can connect to the Internet, anywhere in the world. 
The cloud computing system is not a unique technology, but consists of three basic services [18]:

- Software-as-a-Service (SaaS) includes licensing software applications to users. Licenses are usually issued through a pay-as-you-go or on-demand model.

- Infrastructure-as-a-service (IaaS) includes a method for delivering everything from operating systems to servers and storage via IP-based connectivity, as part of an on-demand service. Clients can avoid the need to purchase software or servers and instead acquire these resources in an external on-demand service.

- Platform as a Service (PaaS) is considered to be the most complex of the three layers of cloud computing. PaaS shares some similarities with SaaS, and the primary difference is that instead of delivering software online, it is actually a platform for creating software that is delivered over the Internet.

The IaaS service is an appropriate solution to the problem posed before. Users of this service can obtain storage, processing, networks and other basic computer resources, and use them by deploying and running arbitrary software [19]. By using cloud computing resources and services, even modest devices with limited computing capabilities, such as things in the IoT, become able to perform the complex calculations needed to effectively perform the assigned task. Everything they need is their equipment with the appropriate sensors and actuators, and their decision-making capabilities can be facilitated by the almost endless computing capabilities of the cloud. The synergistic effect of IoT and cloud computing, which emphasizes the positive aspects of these technologies, and by interacting reduces or even cancels their Cloud of Things not only enables the discovery and integration of things related to the Internet, but also their offer as a resource. In doing so, things can not only be discovered and combined, but also provided as a service to meet the agreed requirements of users

\section{Cloud of Things}

Cloud of Things (CoT) is a high-performance cloud based IoT application platform that allows connecting our IoT enabled devices and remotely monitor, manage and control them. It represents the next step in processing and analysing the data and creating more usefulness from the data generated by IoT by allowing the development of more advanced smart applications.

As an upgrade to basic cloud computing services for building, storing, creating and using data and applications, i.e., SaaS, IaaS and PaaS, different models and forms of CoT services are interconnected by different network environments:

- Sensing-as-a-service,

- Big-Data-Analytics-as-a-Service,

- Database-as-a-service,

- Identity-and-Policy-Management-as-a-service,

- Video-Monitoring-as-a-service,

- Data-as-a-service,

- Sensor-as-a-service,

- etc.

CoT not only enables the discovery and integration of things related to the Internet, but also their offer as a resource. In that way, things can not only be discovered and combined, but also provided as a service to meet the agreed requirements of users. This approach envisions new scenarios and innovative, ubiquitous value-added applications, revealing the world of CoT to every user, customer, and potential service provider, thus enabling an open market of things [21].

\section{Conclusion}

The Internet of Things, realized at the primitive level of connected things with poor computing capabilities, has brought many possibilities that make our everyday lives smart. It's positioning on a robust, cloud platform, which could serve as an effective backbone for achieving a network of sensors and actuators that can be used to improve the performance of connected devices, would bring added value to these already effective technologies.

Cloud of Things represents an integration of the Cloud platform, Cloud infrastructure and IoT middleware. Cloud platforms are the components responsible for providing IoT with the necessary and current requirements, such as realtime processing, scalable storage and global access, as well as expanding towards other capabilities such as machine learning. The cloud infrastructure provides the storage, networking, and computing resources needed by IoT and Cloud platforms. Finally, IoT middleware provides a layer of abstraction for basic IoT devices, as well as mechanisms for interacting with Cloud Computing. However, given that this is an emerging technology, further work is needed to mitigate the challenges of the practical implementation of IoT in the cloud. 


\section{References}

[1] https://waag.org/en/article/we-live-information-age-what-does-actually-mean, (2013). Zandbergen, D. We live in an Information Age: What does that actually mean?, Accessed on: 2021-10-02

[2] Zadeh, S. K., Veisi, A. G., Zadeh, M. K. (2013). Do We Live in an Information Society? Does It Matter? International Journal of Advanced Research, Vol.1, No. 3, pp. 362-366. ISSN NO 2320-5407.

[3] Ou, M. S. (2016). Do we live in an "information society"?. University of London.

[4] https://healthit.com.au/how-big-is-the-internet-and-how-do-we-measure-it, (2020). How Big is the Internet, and How Do We Measure It, Accessed on: 2021-10-15

[5] Ashton, K. (2009). That "Internet of things" Thing. RFID Journal, Vol. 22, No. 7, pp. 97-114.

[6] Gubbi, J., Buyya, R., Marušić, S., \& Palaniswami, M. (2013). Internet of Things (IoT): A Vision, Architectural Elements, and Future Directions. Future Generation Computer Systems, Vol. 29, No. 7, pp. 1645-1660.

[7] Stankovski, S., Ostojic, G., Laslo, T., Stanojevic, M., \& Babic, M. (2019). Challenges of IoT Payments in Smart Services, Proceedings of the 30th DAAAM International Symposium, pp.0004-0009, B. Katalinic (Ed.), Published by DAAAM International, ISBN 978-3-902734-22-8, ISSN 1726-9679, Vienna, Austria

[8] Majstorovic, V[lado] \& Rakic, K[resimir] (2017). Internet of Things and Social Media: Tools of a Successful Information Organization, Proceedings of the 28th DAAAM International Symposium, pp. 0295-0298, B. Katalinic (Ed.), Published by DAAAM International, ISBN 978-3-902734-11-2, ISSN 1726-9679, Vienna, Austria

[9] https://www.cisco.com/c/r/en/us/internet-of-everything-ioe/internet-of-things-iot/index.html, (2017). Cisco Internet of Things, Accessed on: 2017-08-27

[10] Atzori, L., Iera, A., \& Morabito, G. (2010). The Internet of Things: A Survey. Computer Networks, Vol. 54, No. 15, pp. 2787-2805.

[11] Efremov, S., Pilipenko, N., \& Voskov, L. (2015). An Integrated Approach to Common Problems in the Internet of Things. Procedia Engineering, 100, 1215-1223.

[12] Shrouf, F., Ordieres, J., \& Miragliotta, G. (2014). Smart Factories in Industry 4.0: A Review of the Concept and of Energy Management Approached in Production Based on the Internet of Things Paradigm. Proceedings of the 2014 IEEE International Conference on Industrial Engineering and Engineering Management, pp 697-701. IEEE.

[13] Vermesan, O., et al. (2014) Internet of Things Strategic Research and Innovation Agenda. In: Internet of Things From Research and Innovation to Market Deployment, Vermesan, O., Friess, P. (Eds), pp. 7-142, River Publishers, Aalborg,

[14] Fleisch, E. (2010). What is the internet of things? An economic perspective. Economics, Management, and Financial Markets, Vol. 5, No. 2, pp. 125-157.

[15] Wortmann, F., \& Flüchter, K. (2015). Internet of things. Business \& Information Systems Engineering, Vol. 57, No. 3, pp. 221-224.

[16] Aazam, M., Khan, I., Alsaffar, A. A., \& Huh, E. N. (2014). Cloud of Things: Integrating Internet of Things and Cloud Computing and the Issues Involved. In Proceedings of 2014 11th International Bhurban Conference on Applied Sciences \& Technology (IBCAST) Islamabad, Pakistan, 14th-18th January 2014, pp. 414-419. IEEE.

[17] https://www.investopedia.com/terms/c/cloud-computing.asp, (2020). Frankenfield, J., Cloud Computing. Accessed on: $2021-10-10$

[18] Sunyaev, A. (2020). Cloud computing. In Internet computing (pp. 195-236). Springer, Cham, Switzerland

[19] Mell, P., \& Grance, T. (2011). The NIST definition of cloud computing, Oracle.

[20] Parwekar, P. (2011). From Internet of Things towards Cloud of Things. In 2011 2nd International Conference on Computer and Communication Technology (ICCCT-2011) (pp. 329-333). IEEE.

[21] Distefano, S., Merlino, G., \& Puliafito, A. (2012, July). Enabling the Cloud of Things. In 2012 Sixth International Conference on Innovative mobile and Internet Services in Ubiquitous Computing (pp. 858-863). IEEE. 